\title{
Prefeituras priorizam o desenvolvimento local? Um estudo qualitativo do caso de Montes Claros/MG de acordo com a visão de gestores públicos locais
}

\section{Do Prefectures Prioritize Local Development? A qualitative study of the case of Montes Claros / MG according to the view of local public managers}

\author{
Felipe Fróes Couto \\ Mestre em Administração pela Universidade Federal de Minas Gerais, Professor da Universidade Estadual de Montes Claros, Brasil. \\ felipe.froes@outlook.com \\ http://lattes.cnpq.br/1542783014894190 \\ Ivan Beck Ckagnazaroff \\ Doutorado pela Aston University (1993). Professor da Universidade Federal de Minas Gerais, Brasil. \\ ivanbeck00@gmail.com \\ http://lattes.cnpq.br/6536172803067886
}

RESUMO: O presente artigo parte do pressuposto de que as prefeituras possuem um importante papel na promoção do desenvolvimento local. O trabalho é um estudo qualitativo cujo objetivo é analisar as percepções de gestores públicos no município sobre as dificuldades e limitações da prefeitura de Montes Claros/MG no planejamento, implementação e gerenciamento de ações de desenvolvimento local. Para a coleta de dados e tratamento do tema, foram entrevistadas 15 autoridades locais no período de janeiro a março de 2015. Os entrevistados relataram um cenário em que as preocupações com desenvolvimento local são, na estrutura de gastos das prefeituras, apenas acréscimos não prioritários, pois não estão relacionados aos objetivos delimitados pelos governos estadual e federal, que são as principais fontes de repasse de recurso e de controle governamental. Ações de desenvolvimento local, por não serem consideradas prioritárias no presente caso, são consideradas complementares e recebem tratamento equivalente na administração.

PALAVRAS-CHAVE: Desenvolvimento Local, Prefeituras, Capacidade Administrativa.

ABSTRACT: In this article, it is assumed that the municipalities have an important role in promoting local development. This work is a qualitative study, which goal is to analyze the perceptions of public managers in the municipality about the difficulties and limitations of Montes Claros/MG's prefecture in planning, implementing and managing local development actions. For data collection and treatment, 15 local authorities were interviewed in the period of January to March 2015. Respondents reported a scenario in which concerns about local development are, in the structure of expenses of the city halls, only non-priority extras that are not related to the objectives defined by the State and Federal Governments, which are the main sources of resource allocation and governmental control. Local development actions, once not considered as a priority in the present case, are considered complementary and receive equivalent treatment in local administration.

Key-Words: Local Development, City Hall, Administrative Capacity.

Texto completo em português: http://www.apgs.ufv.br Full text in Portuguese: http://www.apgs.ufv.br

Introdução: a importância do relato ilustrativo de caso

A evolução dos estudos de vários campos científicos, como a nova geografia socioeconômica, mostra que o local não é apenas mais uma dimensão do desenvolvimento, mas sim um lócus em que o desenvolvimento, de fato, ocorre. Falar sobre o local nos leva a uma noção de lugares de encontro, de afinidade, de identidade cultural, em termos de valores e comportamentos (Guerrero, 1996). O local, nesse sentido, contém o passado, o presente e as possibilidades futuras de construção de uma nova realidade, a partir da participação de diferentes atores e do uso dos próprios recursos existentes no local (Andion, 2003).

Segundo Ninacs (2002), o ambiente local em que as pessoas vivem deve ser articulado para permitir a capacitação, melhor qualidade de vida, menos pobreza e menos exclusão social. 0 bem-estar econômico, nesse sentido, é desejável na medida em que todos os membros de uma comunidade podem experimentá- lo. Nessa perspectiva, ao local é atribuída a possibilidade de garantir voz aos indivíduos (ainda que não seja possível afirmar, em termos empíricos, que essa realidade esteja presente em todo e qualquer contexto local) e a plenitude de seus direitos e de seus valores com maior precisão. Admite-se que o contato direto dos indivíduos com o governo local permite maior exercício político, ainda que se dê de forma assimétrica e que não haja garantia que serão todos os grupos locais ouvidos em assuntos de interesse público.

As prefeituras, nesse raciocínio, assumem a responsabilidade de ser a instância mais próxima dos cidadãos. A proximidade física do cidadão de seus governantes, o nível maior de contato e a maior possibilidade de expressão da voz individual tornam o governo local o principal responsável pelo atendimento às demandas locais. É por meio das prefeituras que os cidadãos buscam resolver os problemas do cotidiano, de suas casas e dos 
serviços públicos ofertados. Assim, as prefeituras, além de possuir estruturas de serviços públicos, devem também possuir capacidade de planejar e implementar políticas capazes de transformar a realidade das pessoas. Mas uma grande questão que surge dessas inferências é se os municípios brasileiros possuem capacidade administrativa de trabalhar essas demandas transformadoras locais.

Para o presente trabalho, parte-se do pressuposto de que as prefeituras possuem um importante papel na promoção do desenvolvimento local. O desenvolvimento local é uma abordagem que tem ganhado destaque no meio científico brasileiro, e se adequa ao tema justamente porque tange à atuação dos municípios em experiências de desenvolvimento (Dowbor, 2011; Spink, 2010). Trata-se de um movimento contemporâneo, que se intensificou no processo de descentralização do poder político no Brasil após a Constituição Federal de 1988 (Fauré \& Hasenclever, 2007). Entretanto, a questão da capacidade das prefeituras nesses trabalhos é menos explorada na literatura e carece de casos ilustrativos que referenciem a realidade vivida, já que muitas vezes considerações nesse aspecto ficam restritas a análises secundárias sobre dificuldades na articulação de ações entre prefeitos e atores locais.

A capacidade da prefeitura do município de Montes Claros em trabalhar a questão do desenvolvimento local é o objeto de análise da presente pesquisa. Trata-se de uma cidade de médio porte, que possui aproximadamente 390 mil habitantes (IBGE, 2015) e é localizada na Mesorregião Norte de Minas Gerais - historicamente marcada por políticas que visavam ao desenvolvimento pela industrialização da região, que é fortemente caracterizada pelas secas (Braga, 2008). Além de ser um conhecido polo universitário para a região, o município sedia fábricas de grandes grupos empresariais que são ou já foram beneficiários de incentivos fiscais federais, estaduais e/ou municipais, como o Grupo Coteminas, desde 1969, a Vallée, desde 1980, a Nestlé (com a produção de Leite Moça) desde 1983, a Novo Nordisk, desde 2003, o Grupo Alpargatas desde 2011. Em 2016, foi anunciado que a cidade se tornaria polo de produção de Café em Cápsula a partir da expansão das operações da Nestlé, com a chegada do Café Três Corações e do Grupo RPCi. Por se tratar de uma região caracterizada pelo auxílio das políticas de fomento dos governos Federal e Estadual, a maioria dos estudos locais adota o paradigma do desenvolvimento regional em suas análises, de modo a vislumbrar o município apenas enquanto parte importante da região Norte de Minas Gerais, sem dar um enfoque na atuação das prefeituras como elemento que pode potencializar 0 desenvolvimento local.

O presente trabalho se apresenta, uma vez contextualizado o cenário de pesquisa, como um estudo qualitativo cujo objetivo é analisar as percepções dos gestores públicos do município sobre a capacidade da prefeitura de Montes Claros/MG de planejar, implementar e gerenciar ações de desenvolvimento local. Para tal, foi idealizado um estudo exploratório cuja coleta de dados se deu por meio de entrevistas semiestruturadas. Como problema de pesquisa, ficou definida a seguinte questão: quais têm sido, segundo a visão dos gestores públicos locais, as limitações ao planejamento e implementação de políticas públicas de desenvolvimento local pela prefeitura de Montes Claros/MG? O presente trabalho busca fazer uma contribuição à literatura sobre o tema, levantando dificuldades cotidianas e pontos de vista trazidos por gestores públicos que trabalham diretamente com o desafio de promover o desenvolvimento local. Isso se faz importante uma vez considerada a carência de casos panorâmicos sobre o tema e dado o crescente interesse dos pesquisadores sobre soluções criativas para o desenvolvimento local.

Espera-se que, até o final do presente artigo, sejam caracterizadas as peculiaridades e especificidades do presente caso, para que sirvam de parâmetro de comparação com outros casos de atuações de prefeituras no desenvolvimento local e na articulação entre os atores sociais. Após esta introdução, serão apresentadas delineações teóricas acerca do desenvolvimento local e do papel das prefeituras no desenvolvimento local, os procedimentos metodológicos e, por fim, serão apresentados os dados e suas respectivas análises, seguidos das considerações finais.

\section{Delineando o conceito de desenvolvimento local}

A evolução das teorias de desenvolvimento está historicamente relacionada à dimensão da renda dos indivíduos e ao poder de consumo e acesso a bens materiais necessários à vida. Por isso, conforme Comim e Bagolin (2002), em avaliações de desenvolvimento de determinados lugares ou iniciativas, há sempre uma tendência dos pesquisadores de observar aspectos materiais relacionados à renda - pela simples razão de que analisar dados empíricos e quantificáveis de renda é mais fácil do que pensar o desenvolvimento de forma qualitativa.

A ideia de desenvolvimento, de acordo com Mendell (2002), varia de acordo com o campo da ciência. É possível definir o desenvolvimento a partir de conceitos das ciências econômicas, das ciências políticas e das ciências sociais. Esses conceitos não são necessariamente imbuídos com os mesmos valores e não refletem as mesmas interpretações. Assim, os desenvolvimentos econômico, humano, sustentável, social e, mais recentemente, o desenvolvimento local, podem expressar visões diferentes da mesma coisa (Mendell, 2002).

Este artigo coaduna-se com a posição de Sachs (1993), para quem o desenvolvimento se distingue do conceito de crescimento por ser um conceito pluridimensional, baseado em crescimento social razoável, uso prudente dos recursos naturais e eficiência econômica. Opta-se por uma noção integrada do desenvolvimento, que considera que "o conceito de desenvolvimento sugere uma transformação de estruturas e sistemas que levam à melhoria da qualidade de vida para todas as pessoas que vivem no mesmo território"ii (Ninacs, 2002, p, 16-17). Em outras palavras, adota-se a visão do desenvolvimento como uma mudança na estrutura e sistemas que levam à melhoria na qualidade de vida das pessoas de forma pluridimensional, considerando o uso racional dos recursos naturais. 
Já o desenvolvimento na perspectiva local, para de Carvalho (2013), é uma estratégia de desenvolvimento a partir do lugar, proposta no contexto de municipalização, que deriva de um macroprocesso maior: a descentralização dos Estados modernos. Para a autora, os estados nacionais modernos, em razão da sua grande extensão territorial, são ineficientes para administrar as necessidades econômicas e sociais das comunidades, o que justificou um entendimento de que é necessário dotar de maior autonomia os municípios para que eles possam gerir suas realidades. Para Buarque (1999), similarmente, o desenvolvimento local é, acima de tudo,

(...) um processo endógeno registrado em pequenas unidades territoriais e agrupamentos humanos capaz de promover o dinamismo econômico e a melhoria da qualidade de vida da população. Representa uma singular transformação nas bases econômicas e na organização social em nível local, resultante da mobilização das energias da sociedade, explorando as suas capacidades e potencialidades específicas (p. 9).

De acordo com Martins (2002), entender o desenvolvimento local como endógeno significa assumir que este é balizado por iniciativas, necessidades e recursos locais, que se conduz ao caminho do desenvolvimento e da promoção do bem-estar. De acordo com Brandão, Costa e Alves (2004), uma concepção de desenvolvimento local pode ser vista como uma reafirmação de princípios clássicos do mainstream regional e urbano. Para os autores, trata-se de um retorno sofisticado à velha visão reificada do território, que passa a ter vontade e endogenia, que busca ser atrativo para investidores. Nesse contexto, a proximidade física assume uma destacada condição, pois trata o desenvolvimento como um processo de articulação social, portanto sujeito a fatores históricos e culturais (Brandão, Costa \& Alves, 2004).

Nessa visão, o desenvolvimento local é um conjunto de bases metodológicas que podem ser geridas de forma mais efetiva pelo governo local e estão relacionadas à organização da sociedade, ao empreendedorismo e à parceria e articulação das instituições públicas e privadas - tudo isso com vistas à inclusão social, ao fortalecimento da economia local e à inovação na gestão pública e ambiental (Moura, Melo, Castro, Meira \& Lordêlo, 2002).

Fauré e Hasenclever (2007) entendem que o desenvolvimento local é, de certa maneira, o encontro entre potencialidades e iniciativas de atores tanto públicos quanto privados. Essas iniciativas podem levar à valorização dos recursos locais, ao aumento da especialização e da diversificação produtivas, à promoção e à atração de novos negócios. Podem também contribuir para a formação do capital social pela impulsão dada à cooperação e à parceria entre empresas; à organização de redes entre os agentes públicos e privados para elevar a produtividade do conjunto econômico local e para integrar e divulgar inovações; à vinculação entre as empresas e centros científicos e tecnológicos para melhorar a competitividade.

O papel das prefeituras se torna mais evidente quando se consideram essas bases metodológicas. Gerenciamento de meio ambiente, de recursos, de demandas e, principalmente, a capacidade de articulação e diálogo são tarefas que podem ser mais bem desenvolvidas por aqueles que experimentam e compartilham da realidade e dos lugares em que os atores sociais exercitam a sua influência. Assim sendo, às prefeituras cabem também, seja de forma associada ou não com outros atores não governamentais, a tarefa da articulação entre os atores sociais, considerando a realidade, estudando as inúmeras possibilidades que são aplicáveis ao microambiente, bem como provendo serviços públicos que atendam a propósitos comuns.

Nesse sentido, Franco (2000) entende que o desenvolvimento local deve ser entendido como um modo de promover a criação de comunidades mais sustentáveis, capazes de suprir as suas necessidades imediatas; descobrir o despertar para valorização de suas potencialidades e possibilidades e fomentar o intercâmbio externo, aproveitando-se de suas vantagens.

Já Dowbor (2011) ressalta que o desenvolvimento local é uma noção complexa e não deve ser conceituada a partir de uma lógica economicista, mas a partir de uma abordagem que coloque o ser humano e os interesses coletivos e das maiorias como ponto central. Somente assim se torna possível pensar em um novo modo de promover o desenvolvimento que possibilite o surgimento de comunidades mais sustentáveis, capazes de suprir necessidades imediatas, descobrirem suas vocações e potencialidades para ganhos coletivos.

Destarte, a inclusão ativa dos cidadãos tornou-se uma palavra-chave no discurso sobre políticas de desenvolvimento, e o nível local da política social é de grande importância - uma vez tido o lugar como o contexto onde as pessoas vivem, onde a pobreza e a exclusão são experimentadas de forma mais concreta (Grindle, 2007). Da mesma maneira, é no nível local que as instituições públicas atuam ao lado de várias expressões da exclusão social, confrontando-se com os problemas sociais em sua multidimensionalidade, os interesses conflitantes $e$ as consequências da escassez de recursos (Schulze-Böing, 2010).

Para Cragnolino (2000) e Grindle (2007), ações de desenvolvimento local são aquelas que fortalecem a capacidade das instituições e organizações locais por meio da formação de líderes; criam condições para articulação entre atores; apoiam os atores sociais coletivos no nível local; incentivam alianças locais sobre uma gama de oportunidades de iniciativas de desenvolvimento de forma a aproveitar, da melhor maneira possível, os recursos do local, e melhoram os serviços básicos, infraestrutura e educação para a inovaçãoiii.

Vaz (2010) entende que a chave para se analisar as experiências de desenvolvimento local é a articulação do desenvolvimento com os processos participativos. Para esses autores, a participação apresentou-se como uma estratégia fundamental de redistribuição de poder, riqueza e renda, ou, em outras palavras, é a garantia da inversão de prioridades tradicionalmente adotadas pelos governos, em direção a maiores privilégios para setores que são historicamente empobrecidos e mais excluídos.

Entende-se, neste artigo, tendo em vista tantos conceitos diferentes, que a noção primordial do desenvolvimento local tange, principalmente, à questão da participação social nas decisões de 
desenvolvimento. O desenvolvimento local, portanto, envolve uma série de questões relacionadas a uma somatória de esforços em uma determinada localidade, que se articula para melhor se aproveitar de suas potencialidades e recursos, com vistas à criação de iniciativas que contribuam para a redução das desigualdades. Nesse aspecto, a questão do exercício da cidadania ganha importância e se torna elemento central de análise.

Cabe às prefeituras, portanto, exercer o papel de possibilitar as vias de comunicação, de participação e de cidadania ativa. Contudo, essa necessidade ainda é prejudicada por algumas limitações existentes nos governos locais, principalmente no que tange à estrutura e à capacidade administrativa. As especificidades das prefeituras devem ser levadas em consideração conforme cada caso, mas alguns delineamentos podem ser feitos, de maneira genérica, para que seja possível compreender um panorama geral do assunto no Brasil.

\section{O papel das prefeituras no desenvolvimento local: algumas considerações}

Não é muito difícil visualizar a relação que os indivíduos possuem com suas respectivas cidades. Estas trazem consigo não só construções, mas símbolos, traços de vivências que inúmeras pessoas tiveram e significados únicos que cada pessoa atribui aos determinados lugares. Oliveira (2001), nessa linha, entende que é no local que se encontra maior facilidade para o exercício da cidadania, pois os problemas são mais reais, tangíveis, e é atribuído a cada cidadão o direito de exercer seus direitos com maior propriedade. O local, segundo Martins (2002), deve representar as expressões dos indivíduos e grupos que a compõem, por se tratar da instância mais próxima às pessoas, cuja interação ocorre de maneira mais intensa.

Para Pereira e Herschmann (2003), em todo o processo de desenvolvimento local, as prefeituras municipais têm um papel essencial, pois é a instância mais próxima e direta no que se refere a ações de gestão em um dado ambiente. Cabe às prefeituras, segundo os autores, a tarefa de criar condições para que o conjunto de instituições voltadas para ações de interesse público possa colaborar positivamente na direção do desenvolvimento local. À capacidade empreendedora e de liderança para realizar essas respectivas ações, Milio (2007) atribuiu o termo "capacidade administrativa", que, segundo a autora, diz respeito a quatro ações-chave dos municípios: gerenciamento, programação, monitoramento e avaliação da ação pública, respectivamente. Para a autora, é exatamente a capacidade administrativa do município de implementar ações desenvolvimentistas uma das principais variáveis que levam a resultados positivos (FIG. 01) no crescimento e desenvolvimento econômico (Milio, 2007). De forma geral, pode-se conceituar a capacidade administrativa do município de executar tarefas apropriadas de forma efetiva, eficiente e sustentável (Hilderbrand \& Grindle, 1994).

$E$ quais seriam essas tarefas no caso do desenvolvimento local? Schulze-Böing (2010) sugere a implementação de políticas de inclusão ativa - pois serviços sociais locais podem, de forma mais efetiva, enfrentar os desafios da pobreza, o desemprego e a desintegração social em cidades e regiões. O autor ressalta que essa nova perspectiva local holística é mais apropriada que a lógica tradicional de prestação de serviços em silos separados, de responsabilidade e de processos operacionais apartados, que já não são mais adequados à complexidade e multidimensionalidade dos problemas de pobreza e da exclusão do trabalho nas comunidades mais carentes. Dessa maneira, uma política de emprego e renda pode ser trabalhada em consonância e em sintonia com as políticas de educação, por exemplo. Nesse sentido:

Uma vantagem muito significativa das políticas locais é o fato de poderem integrar os diferentes setores, e articular os diversos atores. A opção pelas políticas integradas já é relativamente pacífica entre a maioria das pessoas que trabalham com organização de políticas locais de desenvolvimento. No entanto, vale a pena enfatizar a flexibilidade que este enfoque exige. Primeiro, a política integrada é um ideal a ser atingido, mas não necessariamente representa um ponto de partida. (Dowbor \& Martins, 2001, p. 46)

O que se entende, a partir desses autores, é que o município deve possuir um papel-chave na efetivação das políticas, de forma democrática e participativa, bem como corrigir as eventuais distorções decorrentes de cada política federal, estadual ou local quando isoladamente analisadas. Conforme Dowbor e Martins (2001), essa mobilização do município pode acontecer em torno de um eixo articulador muito pontual, apreendido pela comunidade. Segundo o autor, as mudanças mais amplas de cultura política de uma cidade podem ser percebidas frequentemente a partir de uma proposta simples que deu certo, gerando capital social para outras atividades.

Para Ninacs (2002), em uma perspectiva de desenvolvimento, dispositivos de participação e representação na política municipal devem coordenar o trabalho em conjunto para garantir o bemestar da comunidade e de seus membros. A coordenação dá origem ao nascimento de redes e exige proficiência no uso de métodos para operação dessas redes, no caso, o diálogo e a parceria. A participação dos membros das comunidades, assim, funciona muito bem se o resultado dos esforços de todos couber dentro de uma abordagem coletiva, na qual o conflito de interesses é superado pela concordância em relação aos objetivos locais.

De acordo com Buarque (1999), as experiências de desenvolvimento local decorrem quase sempre de um ambiente político e social favorável, expresso por uma convergência importante de atores sociais no município ou comunidade em torno de determinadas prioridades e de orientações básicas de desenvolvimento. Essa constatação é similar em Grindle (2007) que, em seus estudos, constatou diferenças significativas no desempenho dos serviços públicos para o desenvolvimento local, descobrindo que as estruturas de incentivos de instituições locais nem sempre estão alinhadas com as pressões para melhorar a qualidade de vida local.

Fauré, Hasenclever e Melo (2007) lembram que, apesar dos poderes e liberdades de ação, o espaço de atuação e de intervenção das prefeituras e das Câmaras municipais é 
relativamente reduzido, tanto pelo efeito da matriz macroeconômica que se impõe a partir do plano nacional, através dos efeitos das grandes políticas setoriais definidas pela União e pelos Estados, quanto pela existência de grandes organismos de apoio e de modernização profissional e setorial que desenvolvem visões e estratégias de interesse próprio. O fato é que os municípios, de acordo com Fauré, Hasenclever e Melo (2007), estão limitados em suas possibilidades de ação local por suas respectivas capacidades financeiras e, da mesma forma, políticas.

Essas limitações financeiras foram analisadas por Grindle (2007), que concluiu, a partir de uma coletânea de experiências de desenvolvimento local, que a ausência de autonomia financeira dos governos locais foi efeito colateral dos fluxos financeiros em governos descentralizados. Segundo explica a autora, em muitos países, os encargos das dívidas dos governos locais se tornavam problemas nacionais. Isso resultou em uma supervisão central da receita local e gestão de despesas, restando pouca autonomia aos governos locais, tornando-os menos proativos na geração de receitas e no aumento da robustez da tributação local. Restou ao governo local, então, apenas exigir maiores partilhas de receitas do governo central.

Essa é a razão pela qual, de acordo com Boisier (2009), há a necessidade da criação de um projeto político que privilegie o local - e isso depende do acúmulo de um poder político que rompa com a relação de dominação advinda da transferência de poder incorporada em um projeto nacional centralizador e criar um poder político que se obtenha via consenso, pacto social, cultura de cooperação e capacidade de criar, coletivamente, um projeto político novo.

Já Dowbor e Martins (2001) entendem que a maior fraqueza dos municípios no processo de desenvolvimento local reside na comunicação, uma vez que uma série de municípios trabalha com marketing político, enquanto outros não se comunicam de forma adequada por falha na organização de informação sistematizada e outros nem sabem que a comunicação é essencial e faz parte dos direitos do cidadão. Isso se traduz no uso comum dos recursos municipais com fins eleitoreiros e sem a intenção de divulgar informações relevantes relacionadas a gastos públicos, transparência e aproximação das prefeituras com os atores sociais locais.

Por fim, Fauré, Hasenclever e Melo (2007) entendem que o fator cultural também pode funcionar como verdadeira restrição da capacidade de dirigir as economias municipais. Conforme os autores, as autoridades políticas locais, por muito tempo, se contentaram em conviver com um meio empresarial tradicional, formado por um conjunto de empresas de pequeno porte, cujo objetivo não é crescer, mas manter-se, fornecendo para mercados locais e evitando o risco. A produtividade e a competitividade se tornaram mandamentos para empresas, e isso tem cada vez mais influenciado a natureza das demandas ao governo local. Com o advento da globalização, modificaram-se os cenários e novos desafios foram apresentados às municipalidades, forçando as prefeituras a agirem agora em um ambiente cada vez mais dinâmico.

Em termos de capacidade administrativa, as ideias propostas sugerem uma série de novos desafios para as prefeituras no que concerne tanto à estrutura administrativa quanto ao portfólio de serviços ofertados e fontes de participação social. Entretanto, nenhum desafio parece menor do que a necessidade da criação de meios para o desenvolvimento de um projeto político de desenvolvimento local, que seja resultado das forças de participação social local. Pensar na possibilidade de planejamento de políticas multisetoriais e meios de integração entre os serviços providos demandam estruturas próprias de planejamento, e isso está sujeito, conforme visto, às restrições e limitações encaradas pelas prefeituras: sejam elas de ordem econômica (orçamentária); política (dependência de outros entes federativos) ou mesmo de capacidade gerencial (capacidade dos prefeitos de exercerem atividades "empresariais", ou, em outros termos, realizar atividades e projetos empreendedores no exercício da função pública).

\section{Percurso metodológico}

A escolha pelo estudo de caso qualitativo se deu em função de ser o estudo de caso uma investigação empírica que leva a investigações de fenômenos contemporâneos em profundidade, especialmente quando há pouca inteligibilidade na compreensão de processos na complexidade social nas quais estes se manifestam (Yin, 2015). Assim, tanto em situações problemáticas, como em situações bem-sucedidas, a metodologia é aplicável pressupondo a existência de um corpus teórico prévio que será analisado ao longo da investigação, e admite em outros casos a construção de teorias a partir dos achados da pesquisa realizada.

Em busca de uma justificativa para a escolha do presente método, apontam-se as cinco justificativas indicadas por Yin (2015) - que são: a) de que esses tipos de pesquisa são viáveis quando o caso representa uma situação decisiva para testar uma teoria bem formulada, seja para confirmá-la, seja para refutá-la ou para estendê-la; b) quando o caso representa uma situação rara ou extrema, o que é mais comum na psicologia clínica; c) quando o caso é representativo ou típico, que retrata a realidade de diferentes contextos caracterizados por circunstâncias semelhantes; d) quando o caso se mostra revelador a partir da possibilidade de observação de um fenômeno anteriormente inacessível à investigação científica, e e) quando o estudo de caso único é longitudinal, utilizado como introdução a um estudo mais apurado -, e optou-se pela justificativa "c", dada a possível similaridade do caso a outros municípios brasileiros.

Pela opção qualitativa da presente pesquisa, primou-se pela profundidade das entrevistas em detrimento da representatividade estatística do caso. Assim, para a coleta de dados e tratamento do tema, foram entrevistadas, no presente caso, 15 autoridades locais diretamente envolvidas com atividades de fomento ao desenvolvimento do município no período de janeiro a março de 2015. Esse número de entrevistas não garante a possibilidade de 
generalização das opiniões ao conjunto de sujeitos da pesquisa, mas permite a esquematização do cenário como caso de referência - de acordo com os objetivos propostos neste relato. $\mathrm{O}$ grupo de autoridades políticas é composto por representantes de 5 secretarias municipais, 6 vereadores locais, 2 representantes de instituições de apoio (Conselho de Desenvolvimento Econômico de Montes Claros e Associação dos Municípios da Área Mineira da SUDENE) e 2 representantes de autarquias federais (SUDENE e Banco do Nordeste do Brasil). Foram também realizadas duas tentativas frustradas de entrevista junto ao prefeito do município. Os respondentes serão identificados pela sigla "AM" (autoridades municipais).

As entrevistas semiestruturadas abordaram temáticas específicas, que tinham como objetivo estimular a condução da interação com os participantes. Foram empregados roteiros distintos conforme os grupos de interesse. Após a transcrição das entrevistas, os dados foram tratados mediante análise qualitativa de conteúdo que consiste, segundo Bardin (2008), num conjunto de técnicas sistemáticas de análise de comunicação que visa obter a descrição do conteúdo das mensagens e indicadores (quantitativos ou não) que permitam a inferência de conhecimentos relativos às condições de produção e reprodução dessas mensagens. Os procedimentos foram o de leitura sistemática e organização do conteúdo das entrevistas, seguidos da identificação e análise de conteúdo, conforme observado nas próximas seções. Serão analisados, nas seções seguintes, aspectos como a estrutura administrativa, protagonismo de lideranças sociais, aspectos financeiros-orçamentários, técnicoburocráticos entre outros.

\section{Os desafios da falta de estrutura e de planejamento no executivo municipal}

Um dos primeiros aspectos relacionados à capacidade administrativa de planejar e implementar políticas públicas de desenvolvimento local diz respeito à estrutura administrativa dedicada para esse objetivo. Nesse sentido, tanto maior a capacidade de planejamento e de ação quanto mais bem estruturada a administração e os meios de atendimento à participação da sociedade. No presente caso, a prefeitura de Montes Claros/MG é composta por 12 Secretarias, a maioria voltada para a própria estrutura interna da prefeitura, sendo 04 destinadas à prestação de serviços; 6 voltadas para a sua estrutura interna e apenas 2 voltadas para o planejamento de ações de desenvolvimento socioeconômico. A questão do desenvolvimento local é tratada pela Secretaria de Desenvolvimento Sustentável, que é a responsável pela temática relacionada ao desenvolvimento, é subdividida entre as Secretarias Adjuntas de Desenvolvimento Econômico, Meio Ambiente, Agropecuária e Abastecimento e Agricultura Familiar.

FIGURA 01 - Estrutura das Secretarias da Prefeitura de Montes Claros

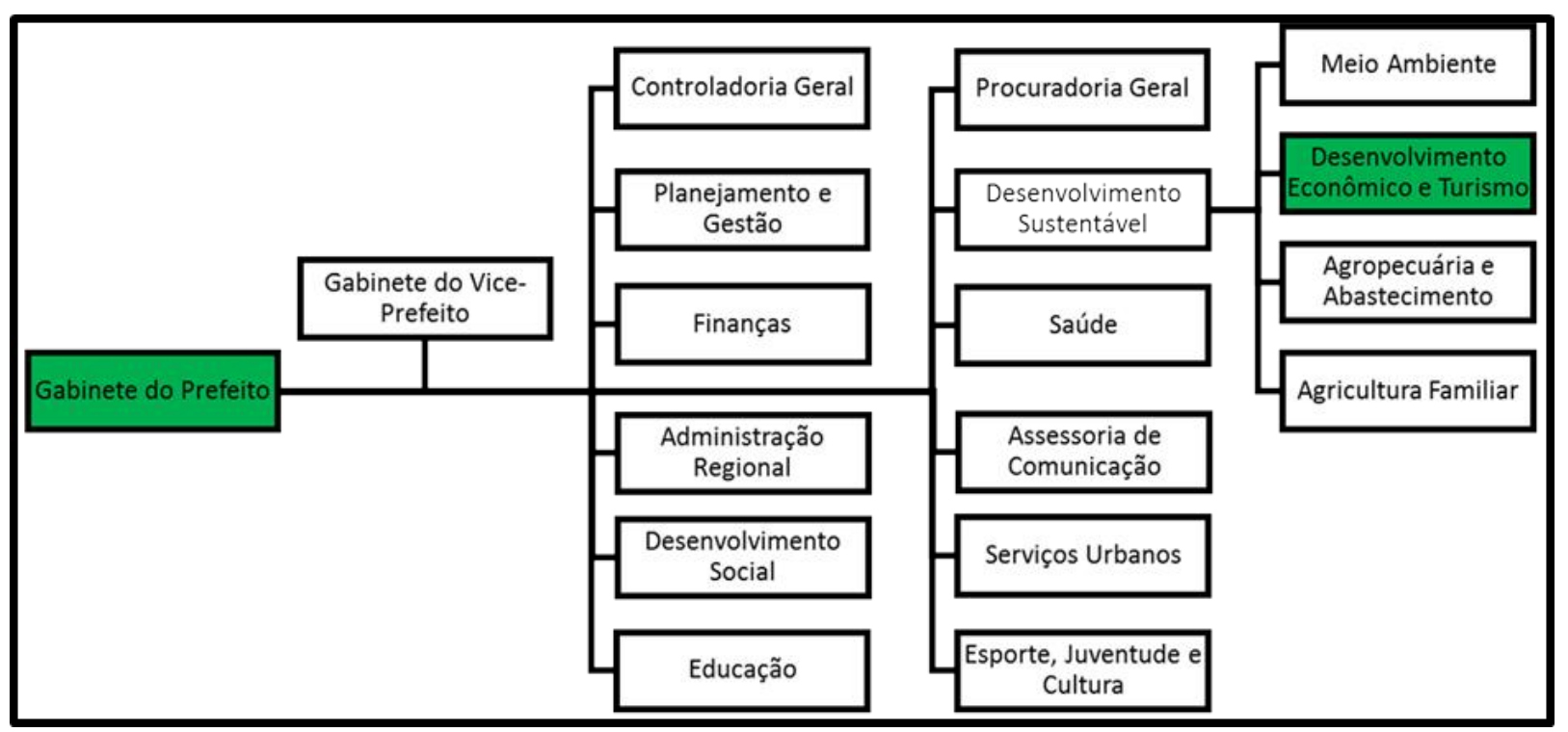

Fonte: Elaboração própria, 2015.

Nessa estrutura de órgãos municipais, a Secretaria de Desenvolvimento Econômico e Turismo, órgão público criado em 2013, é o único órgão que visa a articulação entre os atores sociais e econômicos municipais e do entorno para potencializar o proveito das capacidades locais, e desempenha o papel de encontrar meios para dinamizar e incrementar a economia local. É uma das menores secretarias entre as estabelecidas no município (são menos de 10 colaboradores, entre servidores e cargos de confiança). Apesar de ser uma secretaria de grande importância no contexto municipal, uma vez que busca a articulação das forças econômicas locais para melhorar a oferta de emprego e a qualidade de vida da população, ainda se trata de um órgão recente da prefeitura, que encontra alguns problemas em relação à definição de sua própria existência. Há dificuldades em relação ao diagnóstico de potencialidades locais, potenciais parcerias e de ações que promovam o melhor uso dos recursos locais. Os membros da própria secretaria reconhecem a dificuldade da gestão municipal em priorizar o tema do desenvolvimento local, visto que esta possui obrigações definidas pela União e pelo Estado.

“Na administração pública tem cinco obrigações do Município. O Estado Público é obrigado a investir na educação, saúde, assistência social, segurança pública e finanças. Como é que vão 
os recursos públicos. Essas são as cinco obrigações. Tudo que sai disso aí, é o que você está agregando, é algo novo. Isso aí é o que todo prefeito se preocupa! Todo! Esse movimento econômico, desenvolvimento ambiental, certo? Gerar criatividade nos pequenos negócios, trazer mais indústrias, criar esse mercado diferenciado, vender uma cidade bacana! Né? Como todo mundo gostaria de ter! Isso é um complemento! Isso é se der para fazer!" (Entrevistado AM1, 2015)

A análise desse trecho indica alguns aspectos relacionados às limitações municipais indicadas por Fauré, Hasenclever e Melo (2007) e Grindle (2007). Os autores ressaltam que, muitas vezes, o espaço de atuação e intervenção das prefeituras e das Câmaras municipais na economia local é reduzido pelas políticas setoriais definidas pelos Estados e pela União e pelas limitações financeiras. Essa limitação, em termos práticos, diz respeito à ausência de participação dos municípios no planejamento das políticas públicas e a sua baixa participação na arrecadação, que é centralizada pelos demais entes federativos. Isso acaba prejudicando, a depender da capacidade fiscal local, a criação de grandes estruturas de articulação e dinamização da economia local, como a criação de conselhos, órgãos consultivos e outros mecanismos de participação. O resultado disso no caso analisado é que questões do desenvolvimento deixaram de ser prioridade para o município, que pouco investe nesta questão.

Pela ausência de servidores e de um corpo técnico especializado suficiente para atuar na questão do desenvolvimento local, a complexidade do tema também constitui outra limitação observada, visto que até mesmo conceituações básicas se tornam dilemas, conforme se segue:

"Você vê que o processo de desenvolvimento é um negócio complexo. Como é que você vai fazer para as pessoas viverem bem? Esse é um processo lento, esse é um papel de quem está hoje, como vocês, novos, começando, de encarar o negócio sem fantasia. O papel nosso aqui, é uma secretaria pequena de articulação, é muito mais do fazer com que os outros possam estar trabalhando, fazendo com que as coisas aconteçam... As obras, né? A questão ambiental, o diagnóstico ambiental... procurando ser uma cidade sustentável. Quais são as ações que nós podemos fazer? A não ser, ser chato! Que é cobrar dos outros! Não tem papel mais chato do mundo... Eu não posso chegar aqui e achar que está tudo bem. O negócio está aqui na minha frente e eu fingir que nada está acontecendo." (Entrevistado AM1, 2015).

"Nós temos metas de gerar... Não sei quantos empregos. São METAS! Como é que vai ser percebido isso? Como é que isso vai acontecer? Quais são as ações que precisam ser desenvolvidas? Com quem nós vamos discutir? Quem é que vai implantar isso? Brasileiros em geral, gosta de fazer, gosta de planejar, mas não gosta de executar. Porque é uma tradição nossa, se decide de cima para baixo. Vêm, impõem e vamos seguindo. Não adianta ficar só estudando, escrevendo, depois engavetar aquilo ali... Temos que pensar! Nós temos dificuldade em pensar e planejar! É uma dificuldade NOSSA, falo para vocês! Como nós vamos começar a estabelecer metas?! O secretário vai ter que estabelecer suas próprias metas? O que tem que ser feito esse ano?! Nós temos obrigação de estar fazendo o melhor, de buscar, exaustivamente, até chegar a hora de colocar as coisas em prátical Por exemplo, quais são os setores que nós precisamos apoiar mais? O que é mais importante para Montes Claros? Como vou saber?" (Entrevistado AM3, 2015)

No caso do município de Montes Claros, a estrutura organizacional criada para a articulação econômica entre os atores sociais encontra dificuldades relacionadas ao planejamento e implementação de ações de desenvolvimento local. Os entrevistados afirmam que 0 ato de planejamento de ações de desenvolvimento é um tema complexo, que demanda grandes estruturas de análise que não se encontram disponíveis na prefeitura, e que a mera articulação entre os atores sociais locais não parece uma ação atrativa para a promoção do desenvolvimento local. Essa limitação na integração entre os diferentes planejamentos é um dos principais problemas existentes nas prefeituras (Schulze-Böing, 2010), e constituem limitações técnicas e de gestão que, uma vez resolvidas, poderiam resultar em resultados mais efetivos em termos de desenvolvimento local e ganhos para a coletividade.

Os trechos destacados nas falas acima indicam certas dificuldades do Governo Municipal para formar uma agenda de melhorias a serem propostas. Entre elas, aponta-se a dificuldade de análise da realidade local, de planejamento e implementação de políticas multissetoriais e de inclusão ativa e superação dos problemas de pobreza nas comunidades mais carentes consideradas ações essenciais para o desenvolvimento local e que podem ser potencializadas pelas prefeituras (Pereira \& Herschmann, 2003; de Oliveira, 2001).

No presente caso, as ações da prefeitura local se limitaram à articulação com os agentes econômicos para encontrar soluções criativas que estimulem o desenvolvimento local, ainda que a prefeitura fosse apenas um agente de estímulo ou "entusiasta dos projetos econômicos". O desenvolvimento local, nesse sentido, ficou condicionado à capacidade empreendedora e aos interesses políticos dos representantes da Administração Municipal, que insistem em ações com agentes externos sem pensar no fortalecimento da estrutura interna. Esse entusiasmo pelas ações econômicas, mais do que um meio, se tornou um fim em si, e deu origem a uma iniciativa de participação popular por meio de mecanismos participativos. A necessidade de instrumentos que indiquem possibilidades de ações e definição de metas para a gestão pública passou a ser exercida através da criação do Conselho de Desenvolvimento Sustentável de Montes Claros (CODEMC), instituído pela Lei nº 4.684/2013, com caráter deliberativo e consultivo, para formular e propor a execução das políticas de desenvolvimento no âmbito municipal. Trata-se de um conselho resultante do benchmarking realizado junto à experiência Maringá-PR, cidade adotada como modelo local de desenvolvimento.

O Conselho de Desenvolvimento Sustentável de Montes Claros passou a ser a instância de participação popular e articulação política entre os diversos agentes econômicos locais, e sua criação trouxe à tona um universo de novos desafios, conforme se verá a seguir.

\section{Sem estrutura interna, com participação externa: desafios na participação popular}

O CODEMC é um mecanismo de participação popular municipal criado com a finalidade de envolver todos os cidadãos e instituições relevantes no contexto econômico de Montes Claros/MG. É composto pelo Plenário, pela Diretoria Executiva e por 5 Câmaras Técnicas: de infraestrutura, de tributos, de meio ambiente, de mobilidade e de segurança. Essas Câmaras Técnicas possuem o objetivo de levantar e propor, através de estudos e projetos, soluções para os problemas de 
desenvolvimento de Montes Claros, em sintonia com as necessidades locais, estabelecendo uma agenda de prioridades definida pelos cidadãos. Sua implementação foi permeada pelo sentimento de "avanço político local" (Entrevistados AM1; AM3, 2015).

"Aqui em Montes Claros foi criado recentemente o Conselho do Desenvolvimento de Montes Claros, que é o CODEMC, é um órgão que tem tudo para solução nessa área também. Ali, são debatidos e discutidos os problemas, propostas de soluções e automaticamente, nas outras reuniões, nós vamos lendo as atas, deliberando ou não. Então você cria um vínculo de fiscalização, igual o Ministério Público." (Entrevistado AM2, 2015)

"Esse conselho recém-criado e eu acho que isso vai trazer um desenvolvimento enorme, porque vai ser mais um órgão que a gente vai ter para integrar a parte civil com a parte pública. Vai ter uma fiscalização e uma cobrança de algo para o futuro. (...) o conselho já está com uma visão maior, maior até do que o executivo. Porque o executivo e o legislativo são pessoas que estão aqui pelo voto, e que são passageiros. E esse conselho é permanente e ele vai estar olhando para nossa cidade, com um olhar lá para o futuro. Então, a partir de agora eu creio que nós vamos ter de fato, um conselho que possa fiscalizar e olhar de perto essa questão das empresas." (Entrevistado AM6, 2015)

Percebe-se que a sua criação causa um sentimento positivo nas autoridades políticas locais, visto que muitas mostravam acreditar no potencial de mudança da iniciativa e na possibilidade de um canal de diálogo e de decisão coletiva. Isso é muito importante considerando que a participação e a criação de canais de diálogo são condições sine qua non de sucesso em processos de desenvolvimento local (Ninacs, 2002). Entretanto, embora a criação do conselho com seus propósitos tenha obtido a aprovação dos entrevistados, não se percebe o reflexo dessa aceitação nas reuniões das diferentes câmaras técnicas do Conselho. A título de exemplo, na Câmara Técnica Orçamentária e Tributária, até o dia 26 de janeiro de 2015, 4 reuniões tinham sido feitas, com média de 5,5 participantes por reuniãoiv.

As razões desse aparente insucesso foram indicadas por alguns entrevistados. A hipótese indicada pelo governo local é a de que o Conselho é recente e ainda não foi propriamente absorvido entre os atores sociais e econômicos locais (Entrevistados AM1; AM4; AM7; AM9). Outra hipótese foi sugerida pelos entrevistados e se relaciona a dois fatores específicos: que o Conselho não surgiu de uma iniciativa popular e que não há lideranças sociais populares encabeçando a iniciativa (Entrevistados AM5; AM11; AM13; AM14; AM15).

$A$ análise das entrevistas indica um cenário em que existe dificuldade no planejamento de políticas públicas, além de meios de comunicação incipientes. É perceptível uma ausência de uma estrutura hábil ao planejamento robusto das políticas municipais no Executivo, as iniciativas de participação populares ainda não trazem respostas consistentes aos clamores sociais. Não foram identificadas ações de capacitação da comunidade - o instrumento de consulta foi estruturado sem a preparação prévia da comunidade para esse tipo de inovação.

Um último fator evidente ao longo das entrevistas é a necessidade que os entrevistados sentiram, ao longo de suas reflexões, de um projeto político comum à comunidade, que norteie os caminhos para o desenvolvimento local. A criação de um projeto político comum que privilegie o local permite um olhar mais adequado sobre a realidade cotidiana, identificando e direcionando a necessidade da decisão coletiva a determinados atores e garantindo, por meio de procedimentos, a participação de determinados grupos de interesse na decisão política.

"É melhor você puxar um cavalo do que empurrar um cavalo, você concorda? Então você tem que ter líderes que tenham capacidade de puxar pessoas que gostem da região, que querem o bem-estar das pessoas que estão aqui, que se monte uma coalizão em prol desse desenvolvimento, que não se dará em um curto prazo: vamos falar de nós daqui a vinte anos. (...) O que será Montes Claros daqui a cinquenta anos? SERÁ O QUE NÓS QUISERMOS. Ou o que a contingência deixar acontecer. Então é hora de mobilização, para que pessoas com capacidade de articulação pensem, pessoas bem intencionadas, pensem numa perspectiva evolutiva, empreendedora, socialmente falando, não é? Socialmente e economicamente falando, para Montes Claros daqui a trinta, quarenta ou quem sabe cinquenta anos. O momento está em fazer uma diretriz, um plano de desenvolvimento do Estado para trinta anos, trabalhar em uma perspectiva de longo prazo. Eu acho que temos que trabalhar não só nos preocupando com essas questões vinculantes, mas nos preocupar também, em o que querer para a nossa Montes Claros. Eu acho que isso vai induzir a abrir porteiras para o desenvolvimento." (Entrevistado AM12, 2015)

Isso significa, em outras palavras, que não há um direcionamento para a identificação de quais atores devem compor os grupos decisórios, nem políticas que visem estimular a participação desses grupos, e que a participação deve ser precedida de políticas que visem estimular os cidadãos a se tornarem, efetivamente, parte de uma comunidade - uma comunidade pela qual eles "possuam afeto e zelo" (Entrevistados AM8; AM11; AM14). Até o fechamento desta pesquisa, apenas alguns poucos empresários locais, autoridades políticas e membros da sociedade civil se mobilizaram para a utilização do mecanismo de participação - apesar das boas impressões até então relatadas (Entrevistados AM1; AM3, AM12).

Esse aspecto pode ser considerado problemático quando se acredita que a criação de um poder político via consenso, pacto social, cultura de cooperação e capacidade de criar coletivamente, é requisito para a formação de um projeto político de desenvolvimento local (Boisier, 2009). As ações de planejamento, implementação e controle de políticas de desenvolvimento local devem estar atreladas a um projeto socialmente construído, fundamentado no consenso entre aqueles que experimentam a realidade local (Ninacs, 2002). Isso requer um senso de priorização do diálogo e da formação de um capital social que, conforme visto, ainda não se encontra em estágio maduro o suficiente para a concretização desses ideais. Por essas razões, observou-se que pouca efetividade pode ser atribuída às ações direcionadas para o Conselho Municipal, visto que se trata de ação de longo prazo para problemas que podem ser tratados com estruturas de planejamento mais eficazes.

O presente caso, longe de ter a pretensão de demonstrar uma realidade generalizada dos municípios brasileiros, reflete situações que possuem aspectos interessantes para análises em trabalhos acadêmicos. As dificuldades da gestão eficiente, eficaz e efetiva na gestão pública municipal é tema de grande importância no contexto brasileiro, e pesquisas que trazem aspectos práticos e empíricos sobre essas realidades podem contribuir para a contextualização de um campo que ainda tem muitos avanços a serem conquistados. 


\section{Considerações Finais}

Ao longo do presente artigo, foi possível identificar um cenário de restrições e dificuldades de planejamento de políticas públicas por parte da prefeitura municipal, que se deu principalmente em função da ausência de uma capacidade administrativa e de uma estrutura técnica capaz de atender aos desafios que a abordagem do desenvolvimento local traz. Foram relatadas, principalmente, dificuldades orçamentárias e políticas, uma vez que os entrevistados afirmaram que as preocupações com desenvolvimento local são, na estrutura de gastos das prefeituras, apenas acréscimos não prioritários, pois não estão relacionados aos objetivos delimitados pelos governos estadual e federal, que são as principais fontes de repasse de recurso e de controle governamental. Ações de desenvolvimento local, por não serem consideradas prioritárias no presente caso, são consideradas iniciativas complementares, de articulação local, e recebem um tratamento correspondente na estrutura administrativa local.

Em termos práticos, isso se traduz na incapacidade de planejamento de políticas públicas de desenvolvimento local; na incapacidade de planejamento integrado de políticas públicas locais e na incapacidade de provimento de serviços públicos integrados a um projeto político que contemple o desenvolvimento local. A prefeitura de Montes Claros/MG encontra-se, portanto, como elemento de gestão dos objetivos propostos em um plano central de governo, que demanda resultados de ordem social específicos, independentemente da capacidade administrativa do pessoal, dos meios de comunicação e gestão locais, entre outros fatores.

No presente caso, os gestores da prefeitura associam a questão do desenvolvimento local à cooperação entre os atores econômicos locais, e buscam interagir e influenciar o meio com ações de base política, a partir de processos participativos que surgiram sem um contexto ou cultura preparados para a introdução desse tipo de inovação. Poucos foram os impactos práticos que, de fato, foram percebidos ao longo da pesquisa com a criação do conselho, apesar da boa aceitação que o mesmo apresenta entre os entrevistados. Um cenário como esse levanta algumas provocações que podem constituir futuras pesquisas sobre a temática: a) qual a eficácia da participação popular em estruturas administrativas sem preparo para tal? ou mesmo b) de quem deve partir a iniciativa para a cooperação e para o desenvolvimento local: das prefeituras ou dos próprios atores sociais que integram o contexto? São perguntas que surgem a partir de um olhar pragmático sobre o caso, nas quais se pode levantar uma infinidade de possibilidades.

Apesar da impossibilidade de generalização dos resultados obtidos nesta pesquisa, muitos dos pontos aqui abordados levam a discussões que podem ser tratadas em outras realidades, como os moldes de interface entre o Estado e a sociedade local e a forma de planejamento de políticas e de estruturas administrativas visando a análise das realidades locais.

Contribuições teóricas também podem ser identificadas a partir do caso relatado, que nos ilustra a questão do desenvolvimento local como resultado de dinâmicas políticas locais individualizadas, com características próprias de cada contexto. São precisamente essas dinâmicas que influenciam as formas pelas quais agem as prefeituras em relação ao desenvolvimento do município. Entretanto, uma série de desafios se impõem antes do alcance desse ideal, uma vez que subsistem limitações estruturais, políticas e mesmo culturais que impedem a consolidação de uma administração participativa nos municípios. O caso de Montes Claros/MG retrata a realidade de um município de médio porte, no norte de Minas Gerais, mas traz traços compatíveis com a realidade de muitos municípios brasileiros que buscam se desenvolver, e pode ser um bom caso ilustrativo das dificuldades existentes nas prefeituras para o planejamento e a implementação de políticas e ações de desenvolvimento local.

\section{REFERÊNCIAS}

Andion, C. (2003). Análise de redes e desenvolvimento local sustentável. Revista de Administração Pública, 37(5), 1033-1054.

Bardin, L. (2008). Análise de conteúdo $4^{a}$ ed. Lisboa: Edições, 70.

Boisier, S. (2009). Em busca do esquivo desenvolvimento regional: entre a caixa-preta e o projeto político. Planejamento e políticas públicas, (13).

Braga, M. Â. F. (2008). Industrialização da área mineira da Sudene-um estudo de caso: Montes Claros. Montes Claros, MG: Unimontes.

Brandão, C. A., Costa, E. J. M. D., \& Alves, M. A. D. S. (2004). Construir o espaço supra-local de articulação sócio-produtiva e das estratégias de desenvolvimento. Belo Horizonte: CEDEPLAR.

Buarque, S. C. (1999). Metodologia de planejamento do desenvolvimento local e municipal sustentável. Brasília, junho de.

Cidades, I. B. G. E. (2015). Instituto Brasileiro de Geografia e Estatística.

Comim, F., \& Bagolin, I. (2002). Aspectos qualitativos da pobreza no Rio Grande do Sul. Ensaios FEE, 23 (Especial).

de Carvalho, J. S. (2013). Conselhos municipais: sua contribuição para o desenvolvimento local. Anais: Encontros Nacionais da ANPUR, 8.

de Franco, A. (2000). Porque precisamos desenvolvimento local integrado e sustentável. Instituto de Política.

de Oliveira, F. (2001). Aproximações ao enigma: o que quer dizer desenvolvimento local?. Pólis.

Dowbor, L. (2011). Governabilidade e descentralização. Revista Paranaense de Desenvolvimento-RPD, (83), 65-84.

Dowbor, L., \& Martins, L. (2001). A comunidade inteligente: visitando as experiências de gestão local. Instituto Pólis.

Fauré, Y. A., \& Hasenclever, L. (2007). Caleidoscópio do desenvolvimento local no Brasil: diversidade das abordagens e das experiências. Editora Epapers.

Fauré, Y., Hasenclever, L., \& Martins de Melo, L. (2007). Configurações produtivas locais e desenvolvimento municipal: explorações no interior fluminense.

Grindle, M. S. (2007). Going local: decentralization, democratization, and the promise of good governance. Princeton University Press.

Guerrero, M. G. (1996). La red social como elemento clave del desarrollo local. Lisboa: Sociedade Portuguesa de Estudos Rurais.

Hilderbrand, M. E. and Grindle, M. S. (1994), Building sustainable capacity: challenges for the Public Sector, Harvard Institute of International, Cambridge, MA.

Lei $n=3.502$ de dezembro de 2005 (2005). Altera a redação dos arts. 4ำ $5^{\circ} \mathrm{e}$ $7^{\circ}$ da Lei $n^{\circ} 2.300$ de 26 de dezembro de 1995 e dá outras providências. Montes Claros, MG. Recuperado em 10 de abril de 2015 de: http://www.montesclaros.mg.gov.br/desenvolvimento\%20economico/ div_tur/leis/ lei_3502_05.pdf.

Lei no 4.684/2013 (2013). Cria o Conselho de Desenvolvimento Sustentável de Montes Claros - CODEMC, e dá outras providências. Montes Claros, MG. Recuperado em 10 de abril de 2015 de: http://leisdemoc. blogspot.com.br/2014/05/lei-n-46842013.html.

Martins, S. R. O. (2002). Desenvolvimento local: questões conceituais e metodológicas. Revista Internacional de Desenvolvimento Local, 3(5), 5159 .

Mendell, M. (2002). Qu'est-ce que le développement. TREMBLAY P.-A., TREMBLAY M. et S. TREMBLAY avec la collaboration de M. TRUCHON (dir.), Développement local, économie sociale et démocratie, Sainte-Foy: Presses de I'Université du Québec, 69-84.

Milio, S. (2007). Can administrative capacity explain differences in regional performances? Evidence from structural funds implementation in southern Italy. Regional Studies, 41(4), 429-442. 
Moura, M. S., Melo, V. P., Castro, R., Meira, L., \& Lordêlo, J. A. C. (2002). Gestão do desenvolvimento local, tempos e ritmos de construção: o que sinalizam as práticas. Revista de Administração Pública, Rio de Janeiro, 36(4), 609-26.

Ninacs, W. A. (2002). Le pouvoir dans la participation au développement local dans un contexte de mondialisation. Tremblay, M., et al, 15-40.

Pereira, C. A. M., \& Herschmann, M. (2003, April). Comunicação, cultura e gestão de organizações privadas e públicas na perspectiva do desenvolvimento local sustentável. In Trabalho apresentado no Núcleo de
Relações Públicas e Comunicação Organizacional, XXVI Congresso Anual em Ciência da Comunicação, Belo Horizonte/MG (Vol. 2).

Schulze-Böing, M. (2010). Inclusion and Local Development. Challenges for Local and Regional Government1. Revista de Asistenta Sociala, (4), 147.

Vaz, J. C. (2010). A gestão do desenvolvimento local no Brasil:(des) articulação de atores, instrumentos e território. rap-rio de Janeiro, 44(3), 559-90.

Yin, R. K. (2015). Estudo de Caso-: Planejamento e Métodos. Bookman.

\begin{abstract}
'Notícia
divulgada

em

$16 / 01 /$

<http://www.otempo.com.br/capa/economia/com-tr\%C3\%AAs-

f\%C3\%A1bricas-montes-claros-vira-polo-de-caf\%C3\%A9-em-

c\%C3\%A1psula-1.1213345>.
\end{abstract}

ii Tradução Livre. Texto Original: De façon générale, la notion de développement suggère une transformation des structures et des systèmes menant à une amélioration de la qualité de vie pour toutes les personnes vivant sur un même territoire.

iii Segundo Grindle (2007, p. 3), "Good governance is not simply a function of the structure of intergovernmental relationships. It is, rather, the consequence of new opportunities and resources, the impact of leadership motivation and choices, the influence of civic history, and the effect of institutions that constrain and facilitate innovation". Esse pensamento rompe com as concepções hegemônicas do gestor público distante da sociedade e trazem à baila a noção de que o Estado deve ser mais um ator social para participar ativamente na arena de construções políticas e econômicas junto aos cidadãos.

iv Informações obtidas nas atas de reunião das câmaras técnicas coletadas do CODEMC, Janeiro/ 2015. 